apical buds cause retardation of the growth of gemmæ in the same way as the original ones. Surgical experiments indicate the basipetal movement of inhibitors. Applications of growth hormones, such as indolylacetic acid, indolylbutyric acid and naphthaleneacetic acid in lanolin or in agar blocks, to the cut ends confirm the inhibiting influence of the apical notch and the latter as a centre of synthesis of inhibitors. Positive results for the formation of auxin have been obtained with Avena tests of the extracts of thallus tips. Preliminary experiments with analysis of such extracts by paper chromatography suggest that the auxin involved may be indole acetic acid.

\section{Measurement of Body Radioactivity}

THE papers given at a conference on the measurement of body radioactivity held at Leeds on April $16-17,1956$ (Nature, 178, 172; 1956), have recently been published (Brit. J. Radiology, Supp. No. 7. Pp. vi +130 . London: British Institute of Radiology, 1957. 25s.). Measurements of body radioactivity were originally undertaken to measure the body burden of workers who had been exposed to radium and radon and of patients who had been injected with contrast-media containing thorium. Wider use will now undoubtedly be made of the techniques used in these investigations in determinations of the incorporation of fall-out in human populations. The radium content of the body of a chemist who died at the age of seventy-four after working for thirty-four years with radioactive materials was determined by workers in four independent laboratories. The reasonably good agreement of the results obtained by scintillation counting, ionization chambers and autoradiography gives confidence in the methods.

The admirer of big apparatus will enjoy the description of high-pressure ionization chambers containing 3,000 litres of gas at 20 atmospheres pressure, and of an instrument in which 108 photo-multipliers view the scintillations in 500 litres of liquid with a sensitivity of the $\gamma$-ray equivalents of $10^{-9}$ to $10^{-10} \mathrm{gm}$. radium in equilibrium with its daughter substances. The NaI-TI crystal spectrometer developed by Marinelli and his collaborators shows the trend towards simpler instruments. The volume contains much information on many related topics like background radiation and the radium-content of drinking water in many parts of the world. It is very well produced, but summaries might have been added to the papers.

\section{Algebraic Transformations to a Normal Popula- tion}

AN interesting application of the use of an algebraic transformation of a variable to obtain a normal population is provided by a report, "Distribution conjointe de la température et de l'humidité de l'air au Congo Belge" (Publications de l'Institut National pour I'Etude Agronomique du Congo Belge, Bureau Climatologique. Communication No. 14. Pp. 31. Brussels, 1957), by Dr. F. Bultot. The problem related to the determination of the range within which 95 per cent of values of atmospheric vapour pressure occurred at specified temperatures in the Belgian Congo. Annual and monthly means of temperature and vapour pressure and even annual monthly means of the values for each hour were inadequate to give the limits needed. If the variables are normally distributed the range can readily be determined by drawing the ellipses of bivariate distribution. The actual temperatures and vapour pressures were found, calculating the coefficients of kurtosis and disymmetry, to have quite skew distributions. The values of the logarithms to base 10 of the temperature and of the cube of the vapour pressure, however, were found to be nearly normal. The standard deviations of these quantities, and the correlation coefficient between them, were calculated and the ellipses drawn. Figures for a number of places in the Congo are given, showing the ellipses corresponding to 95 and 99 per cent of the number of observations, with corresponding diagrams obtained by transforming back to direct values.

\section{French Metallurgical Society}

TrE French Metallurgical Society is to hold its autumn meeting in Paris at l'Ecole Nationale Supérieure de Chimie, 11 rue Pierre-Curie, during October 7-12. At the meeting the following awards will be presented : the Grand Medal of the Society to Prof. G. Chaudron, for his services to metallurgy ; and the Rist Prizes to G. Pomey and A. Gueussier. The programme of the meeting includes sessions on metal fatigue, rheology of metals, metallurgical problems posed by atomic power, the physics of metals and the physical chemistry of alloys. Further details can be obtained from the Société Française de Métallurgie, 25 rue de Clichy, Paris 9.

\section{Manchester Literary and Philosophical Society}

THE Manchester Literary and Philosophical Society recently elected the following officers for the year 1957-58 : President, Dr. F. C. Toy ; Vice-Presidents, Miss A. C. Alexander, Sir Geoffrey Jefferson, Prof. J. Kenner, Dr. Norman Smith; Hon. Secretaries, Dr. L. Cohen, F. Willett; Hon. Treasurer, H. Hayhurst; Hon. Librarians, L. L. Ardern, Dr. W. H. Brindley; Hon. Curator, N. G. C. Pearson.

Carlsberg-Wellcome Travelling Fellowships Awards

THE Carlsberg Foundation (Copenhagen) and the Wellcome Trustees (London) announce that the awards of Carlsberg-Wellcome Travelling Fellowships for the academic year 1957-58 (Nature, 179, 658 ; 1957) have now been made. Mr. Jørgen Berger, the Danish Fellow, a member of the teaching staff of the Department of Organic Chemistry, Denmark Pharmaceutical College, will study techniques of organic ultra-microanalysis with Dr. R. Belcher in the Chemistry Department at the University of Birmingham, and Dr. Stephen Paget Lapage, the British Fellow, who is a trainee member of the Public Health Laboratory Service, will work at the State Serum Institute, Copenhagen, on the biochemical and serological identification of enterobacteriaceae.

\section{Oversea Service Division, Colonial Office}

THE following appointments have recently been made in the Oversea Service Division, Colonial Office : C. E. Johnson (chief agricultural officer, Northern Rhodesia), assistant director of agriculture, Northern Rhodesia; J. V. Webdale (agricultural officer, Tanganyika), agxicultural officer, Zanzibar ; J. Blackburn (chemist, Tanganyika), assistant government chemist, Northern Region, Nigeria; A. F. A. Lamb (conservator of forests, Trinidad), chief conservator of forests, Sierra Leone; D. A. Harkin (geologist, Geological Survey Department, Tanganyika), deputy director of Geological Survey, Tanganyika; A. M. 